\title{
Synthetic hTERT DNA Vaccine INO-1401
}

National Cancer Institute

\section{Source}

National Cancer Institute. Synthetic hTERT DNA Vaccine INO-1401. NCI Thesaurus.

Code C142139.

A DNA vaccine consisting of a plasmid encoding a synthetic, full-length sequence of the tumor-associated antigen (TAA) telomerase reverse transcriptase (TERT), which was derived from the consensus sequence from humans and primates and contains two immunogenic mutations (SynCon TERT), with potential immunostimulating and antineoplastic activities. Upon intramuscular administration of INO-1401 in combination with electroporation, TERT protein is expressed and activates the immune system to mount a cytotoxic T-cell (CTL) response against telomerase-expressing tumor cells, which may result in tumor cell death. TERT is the catalytic subunit of telomerase and synthesizes telomeric DNA at the chromosome ends. Telomerase prolongs the functional lifespan of cells via the restoration and maintenance of telomere length. Abnormally activated in tumorigenesis, TERT is expressed by many types of human cancer cells, but its expression is low or non-existent in normal cells. 